\author{
E.В. Дякина* $\quad$ E.V. Dyakina \\ «Зоны особого внимания»: \\ динамика численности сельского \\ населения Западно-Сибирского края \\ в 1932-1933 гг. по данным

\section{"Zones of special attention": dynamics of the rural population of the West Siberian region in 1932-1933 according to tax records} налогового учета

DOI: $10.31518 / 2618-9100-2019-4-6$

УДК 314.8

Выходные данные для цитирования:

Дякина E.B. «Зоны особого внимания»: динамика численности сельского населения Западно-Сибирского края в 1932-1933 гг. по данным налогового учета // Исторический курьер. 2019. № 4 (6). Статья 6. URL: http://istkurier.ru /data/2019/ISTKURIER-2019-4-06.pdf
DOI: 10.31518/2618-9100-2019-4-6

How to cite:

Dyakina E.V. "Zones of special attention": dynamics of the rural population of the West Siberian region in 1932-1933 according to tax records // Historical Courier, 2019, \# 4 (6). Article 6. [Available online:] http://istkurier.ru/data/2019/ISTKURIER2019-4-06.pdf

\begin{abstract}
The article deals with the dynamics of the rural population of Western Siberia during one of the most controversial periods of Soviet history, namely the era of collectivization and industrialization of the country. The first "five-year plans" created a lot of difficulties for historiansdemographers in the availability and reliability of statistical data on population, as they fall into the "inter-census" period of 1926-1937, which might have remained a "blind spot" of Soviet statistics, if not for alternative sources of statistical material collection, such as local urban censuses, livestock censuses, tax accounting data, etc. The reliability of the information of tax records of the rural population is highly appreciated by researchers, and, in their opinion, reflects the most clear picture of the actual situation in the village of the 1930s. Additional difficulties are created by administrative and territorial changes in the borders of the West Siberian region. The article shows the increase and decrease in the number of rural Siberians in the framework of zoning, adopted during tax accounting. Comparison of districts with highest and lowest shares of collectivization in the period of 1932-1933, showed the family size of rural households of the period, including the farm. The influence of hunger on migration processes between the city and the village was determined, but for the period from 1932 to 1933 according to the tax records, the impact of hunger on the decline in population due to natural decline is not so obvious.
\end{abstract}

Keywords: population; rural population of the West Siberian region; famine; collectivization; collective farm.

The article has been received by the editor on 04.07.2019.

Full text of the article in Russian and references in English are available below.

Аннотация. В статье рассматривается динамика численности сельского населения Западной Сибири в один из наиболее противоречивых периодов советской истории, а именно в эпоху коллективизации и индустриализации страны. Первые «пятилетки» создают немало трудностей историкам-демографам в вопросах доступности и достоверности статистических данных при

\footnotetext{
* Дякина Елена Владимировна стажер-исследователь, Институт истории Сибирского отделения Российской академии наук (Новосибирск, Россия), e-mail: Elena-Sok80@mail.ru

Dyakina Elena Vladimirovna, research Intern, Institute of History of the Siberian Branch of the Russian Academy of Sciences (Novosibirsk, Russia), e-mail: Elena-Sok80@mail.ru.
} 
учете населения, так как попадают в «межпереписной» период 1926-1937 гг., который возможно остался бы «слепым пятном» советской статистики, если бы не альтернативные источники сбора статистического материала, такие как локальные городские переписи, переписи скота, данные налогового учета и др. Достоверность информации налоговых учетов сельского населения высоко оценена исследователями и, по их мнению, отражает наиболее четкую картину действительного положения в деревне 30-х гг. прошлого века. Дополнительные трудности создают административно-территориальные изменения в границах Западно-Сибирского края. В статье показаны прирост и убыль численности сельских сибиряков в рамках зонирования, принятого при проведении налогового учета. Сопоставляются данные о районах с наиболее высокой и наиболее низкой долей коллективизации в период 1932-1933 гг., посчитана людность сельских хозяйств того периода, в том числе и колхозных. Определено влияние голода на миграционные процессы между городом и деревней, но на период с 1932 г. по 1933 г. по данным налогового учета влияние голода на снижение численности в связи с естественной убылью не представляется столь очевидным.

Ключевые слова: численность населения; сельское население Западно-Сибирский край; голод; коллективизация; колхоз.

$$
* * *
$$

События, происходившие в годы первых пятилетних планов развития народного хозяйства в СССР, привлекают не одно поколение исследователей. Интерес вызывают как глобальные экономические и социальные преобразования, происходящие в разных уголках страны, так и их влияние на население советского государства, что имеет наибольшую значимость для историков-демографов. Поэтому процессы, протекающие в демографической сфере, вызванные социально-экономическими явлениями, а именно изменение численности сельского населения Западной Сибири в 1932-1933 гг. являются содержанием данной статьи.

Вопросы численности, а вместе с ней рождаемости, смертности, состава и движения населения Сибири в годы форсированной индустриализации и коллективизации с учетом специфики научных интересов прорабатывали: А.А. Бурматов, В.А. Исупов, А.С. Московский, В.Н. Земсков и др. ${ }^{1}$ Они оценивают период начала $30-\mathrm{x}$ гг. XX в. как сильнейший демографический кризис не только на территории Западной Сибири, но и в целом по стране. Демографы констатируют увеличение смертности и снижение рождаемости в городах и сельской местности, лавинообразный рост миграций, с четко направленным вектором деревнягород, что непременно сказывалось на численности сельского населения. На этом временном отрезке она находится в фазе стагнации, а в некоторых районах начинает неуклонно снижаться ${ }^{2}$.

Численность населения рассматривается как базисный показатель, используемый при характеристике, как современной социально-экономической ситуации, так и в ретроспективном анализе. Согласно теории демографического перехода, считается, что в зависимости от типа воспроизводства, в благоприятных социально-экономических условиях численность населения увеличивается или, по крайней мере, не сокращается ${ }^{3}$.

Одним из основных «подводных камней» начала 30-х гг. ХХ. является попадание этого временного отрезка, в так называемый, межпереписной промежуток 1926-1937 гг., где показатели численности населения рассчитывались путем суммирования естественного и механического прироста населения с численностью за предыдущий год, накапливая

\footnotetext{
${ }^{I}$ Бурматов А.А. Демографические потери от голода начала 1930-х гг. в Западной Сибири // Гуманитарные науки в Сибири. 2012. №4. С. 26-30; Московский А.С., Исупов В.А Формирование городского населения Сибири (19261939 гг.). Новосибирск, 1984. 168 с.; Земсков В.Н. Спецпоселенцы в СССР. 1930-1960. М., 2005. 306 с.

${ }^{2}$ Исупов В.А. Численность населения Западно-Сибирского края в расчетах сибирских статистиков 1930-х годов // Вестник Новосибирского государственного университета. Серия: история, филология. 2010. Т. 9. № 1. С. $188-200$.

${ }^{3}$ Демографическая модернизация России, 1900-2000 / под ред. А.Г. Вишневского. М., 2006. 608 с.
} 
статистическую погрешность. Обнуление и корректировку данной погрешности как раз и давали переписи населения, проводимые с определенной регулярностью. По мнению большинства ученых-демографов именно переписи представляют наиболее ценный ресурс для всесторонней характеристики истории населения, а в этот период запланированная на 1933 г. перепись так и не состоялась. ${ }^{4}$

Следующим серьезным препятствием в изучении данного вопроса является то, что уровень учета населения в 1930-е гг., по мнению, как современных исследователей, так и статистиков работавших в Западной Сибири в годы первых «пятилеток» был достаточно низким. Несмотря на неудовлетворительную оценку состояния учета естественного движения населения, видные сибирские статистики Н. Солоницын ${ }^{5}$, А. И. Слуцкий ${ }^{6}$, особую сложность видели в учете механического движения населения. Особенно остро, этот вопрос стоит при подсчете сельского населения, так как количество прибывающих и выбывающих на селе никак не фиксировалось. Если для определения численности городского населения Сибири 1930-х гг. успешно использовались локальные переписи, проведенные Сибкрайпланом, данные перерегистрации городского населения, жилищно-коммунальные переписи проведенные Управлением народно-хозяйственного учета Западно-Сибирского края, то наиболее информативными данными по учету сельского населения региона в межпереписной период считаются данные налогового учета и так называемые «переписи скота».

И третье, что существенно затрудняет исследовательскую работу, это «чехарда» в административно-территориальном делении Западно-Сибирского края образованного в 1930 г. из 14 округов бывшего Сибирского края 8 . В период с 1930 по 1934 гг. деление на округа было ликвидировано ${ }^{9}$, районы неоднократно укрупнялись и переименовывались, сельсоветы передавались из одного района в другой, а зачастую присоединялись к городским поселениям. ${ }^{10}$

Цель статьи проанализировать изменение численности и состава сельского населения по данным налогового учета за 1932-1933 г. ${ }^{11}$

Для достижения поставленной цели, во-первых следует рассмотреть динамику численности сельского населения с учетом административно-территориального деления края; во-вторых разобрать причины снижения или увеличения численности в определенных территориальных образованиях; в-третьих рассчитать долю коллективизированного населения и среднюю людность хозяйства в Западно-Сибирском крае.

В документах налогового учета, аккумулирующих количественную и качественную информацию о жителях советской деревни, все районы Западно-Сибирского края объединены в 11 зон (Зерновая западная, Зерновая восточная, Свекло-сахарная, Молочномаслодельная, Конопляная, Горно-животноводческая, Ойротия, Хакассия, Льноводная Северо-западная, Льноводная Северо-восточная, Льноводная Центральная, Овощномолочная, Нарымский округ), в основной массе по принципу преобладающего метода хозяйствования или сельхозпроизводства. Это дает возможность увязать изменения

\footnotetext{
4 Жиромская В.Б. Переписи населения XX как источник по демографической истории России // Демографическая история России и регионов. Новосибирск, 2016. Вып.1. С. 78-95.

${ }_{5}^{5}$ Слуцкий А.И. К вопросу о постановке учета механического движения населения по горпоселениям // Статистика Сибири: сб. статей и материалов. Новосибирск, 1930. Вып.3.

${ }^{6}$ Солоницын H. Динамика численности и социального состава населения городов Кузбасса // Кузбасс. Результаты переписи городского населения 1931 г. Новосибирск, 1931 г.

${ }^{7}$ Исупов В.А. Использование локальных переписей учетов населения в качестве источников по демографической истории Западной Сибири первой половины XX века // Социально-экономический и гуманитарный журнал Красноярского ГАУ. 2019. № 1 (11). С. 206-216.

8 Постановление ВЦИК от 30 июня 1930 г. об образовании Восточно-Сибирского края и о переименовании Сибирского края в Западно-Сибирский край // СУ РСФСР, 1930, №35, ст. 445.

9 Постановление Сибкраисполкома от 2 августа 1930 г. о ликвидации округов в крае // На советском посту. Новосибирск, 1930. №15 (39). ст. 4.

${ }^{10}$ Административно-территориальное деление Сибири / под ред. А.Н. Козионова. Новосибирск, 1966. 219 с.

${ }^{11}$ Государственный архив Новосибирской области (ГАНО). Ф. П-11. Оп. 2. Д. 34. Л. 1-4.
} 
численности населения с преобладающей направленностью экономического развития районов, и таким образом, получить новые данные о динамике демографического развития западносибирского региона.

Овощно-молочная - это пригородная зона, включающая районы вокруг крупных городских или рабочих поселений. Основным занятием жителей Нарымского округа в силу климатических и географических особенностей являлись промыслы, поэтому в источнике он имеет второе название - Промысловый. Исключение составляют Ойротия и Хакассия, в них районы были объединены по этнокультурному принципу. Деление на зоны связано с организационно-производственной структурой сельского хозяйства Сибирского региона, которая должна была представлять сеть агро-индустриальных комбинатов (АИКов) состоящих из колхозов, совхозов, перерабатывающих предприятий объединенных в транспортную, энергетическую и управленческую цепь. ${ }^{12}$ Деление края по экономическому и хозяйственному принципу виделось большевикам более рациональным. Как указывалось выше, в пределах одной зоны могли происходить переименование, перераспределение, укрупнение районов, но границы зон, как правило, не нарушались, хотя бывали и исключения и это можно отследить по изменению численности жителей.

Таблица 1

Численность сельского населения по данным налогового учета за 1932-1933 гг. в Западно-Сибирском крае с учетом зонирования*

\begin{tabular}{|l|c|c|c|c|}
\hline \multicolumn{1}{|c|}{ Сельскохозяйстенная зона } & $\begin{array}{c}\text { Кол-во, чел. } \\
1932\end{array}$ & $\begin{array}{c}\text { Кол-во, чел. } \\
1933\end{array}$ & $\begin{array}{c}\text { Прирост } \\
\text { (убыль) } \\
\text { чел. }\end{array}$ & $\begin{array}{c}1933 \text { г. в } \\
\text { в к } 1932\end{array}$ \\
\hline Зерновая западная & 1605819 & 1641872 & 36053 & 102 \\
\hline Молочно-маслодельная & 840488 & 874147 & 33659 & 104 \\
\hline Овощно-молочная (пригородная) & 488998 & 556249 & 67251 & 114 \\
\hline Льноводно Центральная & 459033 & 508967 & 49934 & 111 \\
\hline Свекло-сахарная & 436699 & 452317 & 15618 & 104 \\
\hline Льноводно Северо-восточная & 431743 & 427154 & -4589 & 99 \\
\hline Горно-животноводческая & 283031 & 288023 & 4992 & 102 \\
\hline Зерновая восточная & 268589 & 273193 & 4604 & 102 \\
\hline Льноводно Северо-западная & 226088 & 232035 & 5947 & 103 \\
\hline Конопляная & 144494 & 154864 & 10370 & 107 \\
\hline Нарымский округ (промысловая) & 112368 & 121403 & 9035 & 108 \\
\hline Ойротия & 108169 & 104927 & -3242 & 97 \\
\hline Хакассия & 100742 & 92393 & -8349 & 92 \\
\hline Всего по краю & $\mathbf{5 5 0 6 2 6 1}$ & $\mathbf{5 7 2 7 5 4 4}$ & $\mathbf{2 2 1} \mathbf{2 8 3}$ & $\mathbf{1 0 4}$ \\
\hline
\end{tabular}

*Составлено по: ГАНО. Ф П-11. Оп. 2. Д. 34. Л. 1-4. В порядке убывания численности населения.

Из таблицы 1 видно, что численность сельского населения с 1932 по 1933 гг. в целом увеличилась на 221,2 тыс. человек. Если учитывать тренды исследуемого временного отрезка, то это очень хороший показатель, так как за период с 1926 по 1937 гг. численность сельского населения Западной Сибири согласно данным переписей сократилась на 209 тыс. человек ${ }^{13}$.

\footnotetext{
${ }^{12}$ Агро-индустриальные комбинаты Сибири. Ч. 1: К вопросу организации агро-индустриальных комбинатов. / ред. М.А. Минеев. Новосибирск, 1930.133 с.

${ }_{13}$ Исупов В.А. Население Сибири между двумя Всесоюзными переписями: 1926-1939 гг. // Вопросы истории Сибири в новейшее время. Новосибирск, 2011. Вып. 1. С. 57-87.
} 
Ученые связывают это с двумя основными факторами. Голод, охвативший в это время, земледельческие районы Советской России и особенно яростно бушевавший на территории УССР, Поволжья и северного Казахстана коснулся и Сибирского региона, существенно затронув в основном жителей сибирского села. В докладных записках 1932-1933 гг. под грифом «секретно» с мест сообщают о многочисленных фактах голода среди колхозников, единоличников, промысловиков; в сельхозартелях и заготконторах ${ }^{14}$. Естественная убыль населения, вызванная голодом, имела место и служила причиной снижения численности сельского населения в некоторых районах Западной Сибири. При этом выталкиваемые голодом сельские жители в поисках более сытого существования и высокого заработка направлялись в города, обуславливая тем самым механическую убыль в сельской местности и механический прирост в городах и пригородах Западно-Сибирского края.

Наибольший прирост сельского населения в абсолютном исчислении можно наблюдать в Пригородной, Льноводно Центральной, Зерновой западной и Молочно-маслодельной зонах, что очевидно связано с благоприятными природными и социально-экономическими факторами и обусловлено в первую очередь миграционной привлекательностью данных районов по сравнению с оставшимися. Эти области являются самыми населенными, в них сосредоточено более $50 \%$ всего населения Западной Сибири. Динамика численности, выраженная в процентном соотношении, подтверждает выявленную тенденцию, так как наиболее высокий уровень увеличения численности населения - $14 \%$ показывает пригородная зона. Так же в процентном соотношении достаточно благополучными выглядят Льноводно Центральная, Конопляная зоны и Нарымский округ.

Далее анализируя таблицу 1 можно увидеть, что в трех зонах наблюдалось снижение численности населения, с наименьшими как абсолютными - 8349 чел, так и относительными - снижение на 8 \%, показателями по Хакассии.

В 1932-1933 гг. в СССР проводилась достаточно жесткая политика коллективизации, поэтому в данных по налоговому учету фиксировалось количество людей ведущих коллективное хозяйство и количество колхозов. Благодаря этому мы можем оценить динамику численности колхозников, колхозов и их долю среди всего сельского населения и сельских хозяйств Западно-Сибирского края.

Данные табл. 2 подтверждают увеличение населения, занятого в колхозах по всей территории Западно-Сибирского края, кроме Хакассии, где количество колхозного населения уменьшилось на 2392 человека в численном эквиваленте, хотя за один год доля занятого в хакасских колхозах населения по отношению ко всем сельским жителям Хакассии выросла на $2 \%$.

Таблица 2

Численностьколхозного населения по данным налогового учета за 1932-1933 гг. в Западно-Сибирском крае с учетом зонирования*

\begin{tabular}{|c|c|c|c|c|c|c|}
\hline \multirow[b]{2}{*}{ Зоны } & \multicolumn{2}{|c|}{1932} & \multicolumn{2}{|c|}{1933} & \multirow[b]{2}{*}{$\begin{array}{l}\text { Дельта } \\
\text { чел. }\end{array}$} & \multirow{2}{*}{$\begin{array}{c}1933 \text { г. в \% } \\
\text { к } 1932\end{array}$} \\
\hline & $\begin{array}{l}\text { Колхозники, } \\
\text { чел. }\end{array}$ & Доля**, \% & $\begin{array}{l}\text { Колхозники, } \\
\text { чел. }\end{array}$ & Доля ${ }^{* * *}, \%$ & & \\
\hline Зерновая западная & 1097448 & 68 & 1205144 & 73 & 107696 & 110 \\
\hline Зерновая восточная & 155320 & 58 & 181925 & 67 & 26605 & 117 \\
\hline Свекло-сахарная & 281231 & 64 & 304703 & 67 & 23472 & 108 \\
\hline $\begin{array}{l}\text { Молочно- } \\
\text { маслодельная }\end{array}$ & 452790 & 54 & 500675 & 57 & 47885 & 111 \\
\hline Конопляная & 76194 & 53 & 88217 & 57 & 12023 & 116 \\
\hline $\begin{array}{l}\text { Горно- } \\
\text { животноводческая }\end{array}$ & 154816 & 55 & 164761 & 57 & 9945 & 106 \\
\hline Ойротия & 47112 & 44 & 48494 & 46 & 1382 & 103 \\
\hline
\end{tabular}

${ }^{14}$ ГАНО. Ф. 47. Оп. 1. Д. 1552. Л. 121, 124, 126, 128, 129, 130. Д. 1787. Л. 5, 8-17, 20, 27, Д. 1851. Л. 2-3, 7, 10, 14, 17, 19. 


\begin{tabular}{|l|c|c|c|c|c|c|}
\hline Хакассия & 50214 & 50 & 47822 & 52 & -2392 & 95 \\
\hline $\begin{array}{l}\text { Льноводно Северо- } \\
\text { западная }\end{array}$ & 85859 & 38 & 108522 & 47 & 22663 & 126 \\
\hline $\begin{array}{l}\text { Льноводно Северо- } \\
\text { восточная }\end{array}$ & 171482 & 40 & 189552 & 44 & 18070 & 111 \\
\hline $\begin{array}{l}\text { Льноводно } \\
\text { Центральная }\end{array}$ & 234676 & 51 & 264573 & 52 & 29897 & 113 \\
\hline $\begin{array}{l}\text { Овощно-молочная } \\
\text { (пригородная) }\end{array}$ & 260772 & 53 & 318545 & 57 & 57773 & 122 \\
\hline $\begin{array}{l}\text { Нарымский округ } \\
\text { (промысловая) }\end{array}$ & 28845 & 26 & 36182 & 30 & 7337 & 125 \\
\hline Всего по краю & $\mathbf{3 ~ 0 9 6 ~ 7 5 9}$ & $\mathbf{5 6}$ & $\mathbf{3 4 5 9} \mathbf{1 1 5}$ & $\mathbf{6 0}$ & $\mathbf{3 6 2 ~ 3 5 6}$ & $\mathbf{1 1 2}$ \\
\hline
\end{tabular}

* Составлено по: ГАНО. Ф П-11. Оп. 2. Д. 34. Л. 1-4

** Во всем сельском населении 1932 г.

**** Во всем сельском населении 1933 г.

Наиболее коллективизируемыми за этот год областями по данным налогового учета являются Льноводная северо-западная - повышение уровня колхозного населения на $26 \%$, Овощно-молочная (пригородная) - на 22 \% и Нарымский округ соответственно на $25 \%$. Хотя по абсолютному показателю лидирует Зерновая западная зона, колхозы которой прибавили 107, 7 тыс. человек. Доля колхозников среди всей массы сельского населения, была наиболее высока в Зерновой западной зоне и составляла в 1932 г. - 68 \% и 73 \% в 1933 г. Наименьшая доля колхозного населения по отношенью к сельскому населению в общем, по данным табл. 2 - в Нарымском округе, как в 1932 г. - $26 \%$, так и в 1933 г - $30 \%$. Это вполне объяснимо промысловой спецификой данного региона.

По всему Западно-Сибирскому краю в 1932 г. было коллективизировано 56 \% сельского населения, что составило в численном выражении 3096, 8 тыс. чел., а в 1933 г. - $60 \%$ жителей сибирской деревни - это 3459,1 тыс. чел. соответственно. Уровень коллективизации за период 1932-1933 гг. составил 12\%, то есть в абсолютном исчислении количество колхозников увеличилось на 362,4 тыс. сибиряков.

Численность колхозных хозяйств и ее динамика пропорциональны численности колхозного населения и дублируют тенденции, выявленные в табл. 2, поэтому нет необходимости приводить ее в данном материале. Но весьма интересным показателем характеризующим численность населения, который можно извлечь из данных по налоговому учету сельских жителей Западно-Сибирского края, является количество едоков приходящихся на одно хозяйство. Эту цифру можно получить путем деления количества жителей в одной зоне, на количество хозяйств в этой же зоне. Полученные данные представлены в табл. 3.

Таблиияа 3

Среднее количество едоков в хозяйстве Западно-Сибирского края*

\begin{tabular}{|l|c|c|c|c|}
\hline \multirow{2}{*}{ Сельскохозяйственная зона } & \multicolumn{2}{|c|}{1932} & \multicolumn{2}{c|}{1933} \\
\cline { 2 - 5 } & $\begin{array}{c}\text { Все } \\
\text { хозйств, } \\
\text { чел. }\end{array}$ & $\begin{array}{c}\text { Колхозные, } \\
\text { чел. }\end{array}$ & $\begin{array}{c}\text { Все } \\
\text { хозяйства, } \\
\text { чел. }\end{array}$ & $\begin{array}{c}\text { Колхозные, } \\
\text { чел. }\end{array}$ \\
\hline Зерновая западная & 4 & 4 & 4 & 4 \\
\hline Молочно-маслодельная & 5 & 5 & 5 & 5 \\
\hline Овощно-молочная (пригородная) & 4 & 4 & 4 & 4 \\
\hline Льноводно Центральная & 4 & 5 & 4 & 4 \\
\hline Свекло-сахарная & 4 & 5 & 4 & 4 \\
\hline
\end{tabular}




\begin{tabular}{|l|l|l|l|l|}
\hline Льноводно Северо-восточная & 4 & 4 & 4 & 4 \\
\hline Горно-животноводческая & 4 & 4 & 4 & 4 \\
\hline Зерновая восточная & 4 & 4 & 4 & 4 \\
\hline Льноводно Северо-западная & 5 & 5 & 4 & 5 \\
\hline Конопляная & 5 & 5 & 5 & 5 \\
\hline Нарымский округ (промысловая) & 4 & 4 & 4 & 4 \\
\hline Ойротия & 4 & 4 & 4 & 4 \\
\hline Хакассия & 5 & 5 & 4 & 4 \\
\hline Всего по краю & $\mathbf{4}$ & $\mathbf{4}$ & $\mathbf{4}$ & $\mathbf{4}$ \\
\hline
\end{tabular}

${ }^{*}$ Составлено по: ГАНО. Ф П-11. ОП. 2. Д. 34. Л. 1-4.

Из таблицы видно, что средняя людность хозяйств в Западно-Сибирском крае 4 человека. Наибольшее число людей приходящихся на одно хозяйство наблюдалось в Молочномаслодельной и Конопляной зонах и составляло 5 человек. За 1932-1933 гг., людность хозяйства в Западной Сибири существенно не изменилась.

Анализ, проведенный в ходе исследования, подтвердил основные тренды периода 30-х гг. $\mathrm{XX}$ в. о стагнации численности сельского населения в Западно-Сибирском крае, ориентации миграционных потоков в сторону городских поселений, увеличении числа коллективных хозяйств и населения вовлеченного в них.

\section{Лumepamypa}

Агро-индустриальные комбинаты Сибири в 6 ч. Ч. 1: К вопросу организации агроиндустриальных комбинатов. / Сиб. краев. пл. комис., Краев. науч.-исслед. ин-т экономики и орг. социалист. сел. хоз-ва; ред. М. А. Минеев. Новосибирск: Тип. Сибполиграфтрест, 1930. 133 с.

Административно-территориальное деление Сибири / под ред. А.Н. Козионова. Новосибирск: Зап.-Сиб. Книжное изд-во, 1966. 219 с.

Демографическая модернизация России, 1900-2000 / под ред. А. Г. Вишневского. М.: Нов. Изд-во, 2006. 608 с.

Жиромская В.Б. Переписи населения ХХ как источник по демографической истории России // Демографическая история России и регионов. Новосибирск, 2016. Вып.1. С. 78-95.

Исупов B.A. Использование локальных переписей учетов населения в качестве источников по демографической истории Западной Сибири первой половины XX века // Социальноэкономический и гуманитарный журнал Красноярского ГАУ. 2019. № 1 (11). С. 206-216.

Исупов В.А. Население Сибири между двумя Всесоюзными переписями: 1926-1939 гг. // Вопросы истории Сибири в новейшее время. Новосибирск, 2011. Вып. 1. С. 57-87.

Исупов В.А. Численность населения Западно-Сибирского края в расчетах сибирских статистиков 1930-х годов // Вестник Новосибирского государственного университета. Серия: история, филология. 2010. Т. 9 № 1. С. 188-200.

Слуцикий А.И. К вопросу о постановке учета механического движения населения по горпоселениям // Статистика Сибири: сб. статей и материалов. Новосибирск, 1930. Вып.3.

Солонищын H. Динамика численности и социального состава населения городов Кузбасса // Кузбасс. Результаты переписи городского населения 1931 г. Новосибирск, 1931 г.

\section{References}

Agro-industrial'nie kombinati Sibiriv $6 \mathrm{ch}$. CH. 1: K voprosu organizacii agro-industrial'nikh kombinatov/ Sib. kraev. pl. komis., Kraev. nauch.-issled. in-t ekonomikii org. socialist. sel. hoz-va; 
red. M.A. Mineev [Agro-industrial complexes of Siberia. In 6 parts. Part 1: To the question about organization of agroindustrial complexes / Siberian regional planning commission. Regional scientific-research Institute of Economics and Organization of Agriculture; Ed. M.A.Mineev]. Novosibirsk: Tip. Sibpoligraftrest, 1930. 133p.

Administrativno-territorialnoe delenie Sibiri [Administrative division of Siberia] / Ed. A.N. Kozionova. Novosibirsk: Zap.-Sib. Knizhnoeizd-vo, 1966. 219 p.

Demograficheskaya modernizaciya Rossii, 1900-2000 [Demographic modernization of Russia, 1900-2000] / Ed. A.G. Vishnevskogo. Moscow: Nov. Izd-vo, 2006. 608 p.

Zhiromskaya V.B. Perepisi naseleniya XX kak istochnik po demograficheskoy istorii Rossii [Population censuses $20^{\text {th }}$ as a source of demographic history of Russia] // Demograficheskaya istoriya Rossii I regionov. Novosibirsk, 2016. Iss.1. P. 78-95.

Isupov V.A. The use of local population censuses as sources for the demographic history of Western Siberia in the first half of the $20^{\text {th }}$ century // Social'no-ekonomicheskiy I gumanitarniy zhurnal Krasnoyarskogo GAU, 2019, № 1 (11). P. 206-216.

Isupov V.A. Naselenie Sibiri mezhdu dvumia Vsesoyuznimi perepisyami: 1926-1939 gg. [Population of Siberia between two all-Union censuses: 1926-1939] // Voprosi istorii Sibiri v noveyshee vremya. Novosibirsk, 2011. Iss.1. P. 57-87.

Isupov V.A. Population of the West Siberian region in the calculations of the Siberian statisticians of the 1930s // Vestnik Novosibirskogo gosudarstvennogo universiteta. Seriya: istoriya, filologiya, 2010, T. 9, № 1. P. 188-200.

Sluczkij A.I. K voprosu o postanovke uchyota mekhanicheskogo dvizheniya naseleniya po gorposeleniyam [To the question of accounting of mechanical movement of the population on settlements] // Statistika Sibiri: sb. stateyimaterialov. Novosibirsk, 1930. Iss.3.

Solonicyn N. Dinamika chislennosti I social'nogo sostava naseleniya gorodov Kuzbassa [Dynamics of the number and social composition of the population of the cities of Kuzbass] // Kuzbass. Rezul'taty perepisi gorodskogo naseleniya 1931 g. Novosibirsk, 1931.

Статья поступила в редакциию 04.07.2019 г. 